\title{
Study on Ideological Characteristics and Development Tendency of Current College Students
}

\author{
Shu Bu \\ Political science and History Institute, Inner Mongolia University for the Nationalities, Tongliao \\ 028043, China
}

Keywords: College students; Ideological characteristics; Development tendency

\begin{abstract}
Ideological and political education of college students is one of important means for modern colleges to enhance students' ideological and ethical quality, cultivate them to establish correct outlook on life and values. Ideological and political education imposes much more significant influences on development of social economy, politics and culture at a potential level. Besides, as popular development of China's college education gradually speeds up, ideological development of college students gradually becomes a key issue which receives social extensive attention. This paper starts from ideological composition of contemporary college students and analyzes major ideological characteristics and prominent development tendency in the development process, in the hope of arousing attention of college students to ideological and political education work and boosting ideological and political education level.
\end{abstract}

\section{Introduction}

Contemporary college students are in the front of social politics, culture and education, so their ideology presents development characteristics of combined diversification and individuation due to influence of Chinese and western cultural conflict and has distinct era brand. Hence, this paper greatly helps study expected development tendency of ideological characteristics of contemporary college students, enhance effects of ideological and political education and improve their ideological and political quality. Therefore, the study also has certain social practical value.

\section{Main components of ideology of contemporary college students}

\section{Political quality}

Political quality of college students mainly refers to ideological trend of college students on the Party, government and the whole nation in the aspect of national administration and spirit construction. Generally, the core of political quality of college students includes socialist core value, spirit of patriotism and collectivism spirit. Favorable ideological and political quality can not just cultivate innovation ability and exploration practice ability of college students in student stage, but also influence their entrepreneurship and employment consciousness after they enter the society and contribute to future development of students.

\section{Ideological quality}

Simply speaking, ideological quality of college students refers to their rational cognition of Marxist philosophy view, scientific world view, correct outlook on life and values during receiving college education. To be more specific, it covers theory of development practice, materialism thought, realistic philosophy of life, democracy, government by law and competitions etc.

\section{Moral quality}

Ideological and moral quality of college students refer to their consciousness and quality of conscientiously abiding by social ethics standards due to influence of social development trend in daily life. "Patriotism, observance of law, courtesy, honesty, solidarity, friendship, devotion and contribution” are basic moral qualities of contemporary college students in behavioral habits. 


\section{Ideological characteristics of contemporary college students}

\section{Own strong ability to receive fresh things and innovation consciousness}

In current stage, under joint influence of ideological and political education and employment education, Chinese college students can explicitly grasp their future development direction and maturely construct their life goal. Chinese colleges set up rich and colorful associations, social practice and competitions etc. Students not just experience joys of college life and train various abilities in activities. Meanwhile, these activities to some extent help college students gradually form creative thinking so that they can better cognize and position themselves. On this basis, they can excavate their potentials and lay a solid foundation for future benign social development. In addition, rapid development of network information technology also creates conditions for students to rapidly receive new things.

\section{Sense of era further intensifies, and sense of responsibility also strengthens}

At present, influenced by socialist core value, most college students have owned firm political development idea and correct political development direction in study and life. They pay attention to Chinese and foreign situations and current politics in time in study and life, actively express their political views on these issues and are full of confidence and expectation for the future of the country. Moreover, after real participation in democratic election, students' interest in democratic election sharply improves. Thus, they further yearn for democracy and pursue life freedom in life and thus generate strong sense of social responsibility and sense of historical mission.

\section{Self-positioning is generally too high and practical ability is relatively poor}

In China, limited by traditional educational concept, colleges have certain defects in ideological cultivation of college students. Modern college students are often deemed as the pride of the whole family and even the village. So, they gradually develop the bad habit of "living on the labor of others" in the learning process. They cannot form correct cognition in comfortable campus life. Their self-positioning is relatively high. Thus, bad effects are caused to social life.

College students are too restless during solving problems and their ability to distinguish things is poor

As the reform and opening-up course deepens, market economy further develops. Free competition trend reinforces. Multiple cultures mutually resist and fuse. So, very important effects on outlook on life, values sand social morality of contemporary college students are generated. On the one hand, their ideology has era characteristics and they are more suitable for development and survival in contemporary society; on the other hand, their ideology is too extreme during handling problems in life. Usually, they have one-sidedness feature and restless social atmosphere, lack critical thinking skills and the ability to solve practical problems. Especially in information explosion era, network information communication and acquisition channels are more complex. Network information quality cannot be guaranteed. Thus, students may be easily influenced by network environment and show idealist tendency of handling affairs. This is not beneficial to students' future development.

\section{Individual consciousness is prominent and collective idea is poor}

Since contemporary society owns very strong openness, this provides broad space and platform for self-personality exhibition. Students' self-awareness continuously intensifies and their social collective collaboration awareness is neglected gradually in individuation exhibition process. Students cognize themselves in study and life and enhance their self-confidence, but wrong orientation forms in personality growth to some extent. Thus, when students' individual interest and social interest happen, they cannot give priority to collective interest, which is to the disadvantage of social stable development.

\section{Psychological enduring capacity is weak}

Influenced by studying experience in favorable circumstances, psychological enduring capacity of contemporary college students is very weak. Once their expected value and reflection of social practice have large deviations, large psychological fluctuations will emerge. Even, students' life safety will be threatened. However, employment situation is increasingly intense in current society. 
Under such circumstance, competitions among students continuously strengthen. Once their psychological enduring capacity is low, they will generate certain suspicion, anxiety, depression, envy and other ideological obstructions in employment competitions. Even they will form pessimistic idea in handling affairs and seriously affect their follow-up life.

\section{Study on ideological development trend of contemporary college students}

\section{Political thought will certainly shift to practice}

Contemporary college students inherit numerous campus upheavals in the last century. Political thought will certainly change significantly under the influence of contemporary social market economy. Political thought shifts to "practice in return" from "extreme in craze" in the last century and "deviation in indifference" in this century. This expresses education introspection in contemporary society, and reflects ideological deposition when society develops to certain historical stage. It is a problem which should be highly valued in ideological and political education work. Thus, each college should make the best use of the circumstance, guide college students develop toward real life and study ideas and facilitate their health growth while carrying out ideological education. It can be seen from the discussion about ideological characteristics of contemporary college students that, in current stage, political thought of college students shift to practice. Ideological trend in two aspects are reflected.

Firstly, students' professional ideal target has started to who the downtrend. Professional ideal is further close to social life practice. In Chinese youth group, college students have rich life ideals, for they receive favorable advanced education. They gradually show bright light with era progress through their knowledge and life ideal woven by patriotism. In different historical periods, social political ideal of college students also has large difference. For contemporary college students, China's society is stable; economy develops rapidly; people's living standards also improve significantly. Thus, social and political thought of college students shifts to national recent development goal, i.e. determined to construct and develop socialist society based on national conditions.

Secondly, students start to oppose theoretical education in the learning process and hope to gain practical education. "Practice is the sole standard to check truth". After receiving philosophical and political education of Marxism-Leninism, college students driven by social employment situation start to pay attention to practical teaching and greatly resist blank sermon education. Contemporary students have started to cognize the importance of spiritual construction in study and life. Only when they really perfect their spiritual world in study can they gradually improve their comprehensive quality and gain advantage in market competitions. Therefore, after contemporary college students learn disciplinary knowledge, they are willing to cultivate their knowledge application ability through social practice, hope to seek the bonding point of life and knowledge in practice and apply what they have learned in actual life. Hence, modern college education institutions should focus on cultivating students; practical ability and facilitate development of their ideology to practical spirit education.

\section{Value standards start to shift to practicability}

Although social and political ideal of college students obviously start to shift to practice under the influence of national education policy and presents a good trend, it is undeniable that drive by market economic competition idea, students' value standard also alters correspondingly. Students gain value orientation through "practicability", which imposes bad impacts on construction of socialist spiritual civilization. Firstly, specialty selection is based on practicability. Influenced by social employment pressure, contemporary college students rarely take into account of their interests and possible contributions to society during selecting specialties, but hope to obtain corresponding return while serving the society and achieving individual value. They train their professional skills according to actual needs of future economy, politics, culture, education and society. Most students choose some specialties with small competitions and large return. This seems to be relatively scientific, but generates certain bad effects in follow-up study. Some students are finally faced with low 
professional level and the awkward situation of unemployment, because they cannot master professional knowledge. Therefore, in ideological and political education, colleges should guide students along with their employment consciousness, correct their bad ideological trend, make them gradually establish correct employment consciousness in campus life and give them the opportunity of secondary employment selection on campus in time. Secondly, college students pursue practicability in terms of interpersonal communication. Contemporary college students have strong consciousness of public relations due to the influence of employment salary level and firmly believe interpersonal relationship generates important effects on career success. Thus, they start to consciously cultivate their interpersonal circles in campus life. Social utility color in interpersonal communication is very dense. Thirdly, they stress practicability in terms of basic living ability. Contemporary college students often have the contradiction of strong sense of independence and low independent living ability. Thus, in order to quickly obtain living experience, they frequently train their living ability and hope to help them in future actual life. This should have been a correct ideological trend, but they learn cooking, beautification and preparation in campus life due to excessive pursuit of practicability. As a result, domestication ideological trend appears, which results in certain bad impacts on specialty study. This event leads to the loss of their sense of competition and entrepreneurial spirit. This goes against their future social work and life. Therefore, colleges should correct students value standard in ideological and political education, prevent their value standard from shifting to practicability, enhance their learning of specialized knowledge, practice and comprehensive quality cultivation so as to lay a foundation for future development.

\section{Conclusions}

In one word, ideological characteristics and development tendency of contemporary college students are influenced by development tendency and react upon further development and innovation of social economy, politics and culture. In the new period of socialist construction, all colleges should start from actual ideological development, stick to regarding students as teaching subjects, actively explore ideological and political education mode which can promote continuous and healthy development of students' ideology, further enhance their ideological and moral construction and cultivate high-quality talents for socialist modernization.

\section{References}

[1] Shan Meiying, Study on ideological characteristics of post-1990s college students and effectiveness of ideological and political education. China Education Innovation Herald, 2012 (25).

[2] Sun Junwei, Jiang Lijie, Shen Jian et al., Study on influence factors ideological characteristics of post-1990s college students and educational management countermeasures. Education Science \& Culture, 2013 (35).

[3] Sun Huafei, Discussion on problems existing in college PE teaching and reform orientation. Sports Time, 2013 (15).

[4] Jing Lixian, Qi Shuli, Selection of group activity paths based on ideological characteristics of college students. Popular Science. Scientific Education, 2012 (3) 